Research Article

\title{
Significance of Supportive HRM Practices and Job Satisfaction towards Work Engagement
}

\author{
Mohammed Ali Akour ${ }^{1, *}$ and Sultan Saqar Alwahaibi ${ }^{2}$ \\ ${ }^{1} \mathrm{~A}$ 'Sharqiyah University, Oman \\ aliakour@yahoo.com \\ ${ }^{2}$ Ministry of Education, Oman \\ sultan82saqar@gmail.com \\ *Correspondence: aliakour@yahoo.com
}

Received: $6^{\text {th }}$ May 2021; Accepted: 21 July 2021; Published: $1^{\text {st }}$ August 2021

Abstract: The main intention is to probe the impression of the HR practices on work engagement. The study has tested the intervening role of job satisfaction in the connection between supportive HR practices (job security and job crafting) and work engagement. In line with this, partial least square (PLS-SEM) through SmartPLS software 3.0 was used to perform the analysis. 576 instruments were disseminated, out of which 465 were received returned, whereas 85 questionnaires were discarded because they were not filled correctly. Therefore, final analysis was executed on 380 responses and the response rate of $80.729 \%$. The current research concluded a significant affirmative link exists among supportive HRM practices towards job satisfaction and work engagement. Findings show that workers of the hotel industry in Oman found time job security and job crafting better sources of job satisfaction and work engagement. Additionally, this research also found significant intervening influence of job satisfaction on the association of job security, job crafting with work engagement. This research has valuable theoretical and practical implications.

Keywords: Supportive HRM Practices; Job Security; Job Crafting; Job Satisfaction; Work Engagement

\section{Introduction}

Since decades, organizations are facing huge complex obstacles like changes in demographics, performance expectations and globalization (El-Kot \& Leat 2008; Chandrakumara \& Sparrow 2004; Othman, 2009). Due to such obstacles, there is a need to manage human resources competitively for strategic survival in the market. Scholars such as Huertas-Valdivia et al. (2019); Chen and Peng (2019) narrate that the hospitality sector, like the hotel industry, focuses on engaged workforce.

Engaged workforce is a source of competitive edge, long-term achievement, and most importantly, financial success (Albrecht et al. 2015; Xanthopoulou et al. 2009). According to Bakker et al., 2011; Schaufeli et al., 2006) that engaged employees deliver dedication, high energy and work with concentration. Disengaged employees are opposite to engaged employees and can be a reason of loss in trillion dollars on yearly basis globally (Christian \& Ellis, 2013).

Mohammed Ali Akour and Sultan Saqar Alwahaibi, “Significance of Supportive HRM Practices and Job Satisfaction towards Work Engagement", Annals of Contemporary Developments in Management \& HR (ACDMHR), Print ISSN: 2632-7686, Online ISSN: 2632-7694, pp. 20-31, Vol. 3, No. 3, $1^{\text {st }}$ August 2021, Published by International Association of Educators and Researchers (IAER), DOI: 10.33166/ACDMHR.2021.03.003, Available: http://acdmhr.theiaer.org/archive/v3/v3n3/p3.html. 
Hence, retaining and hiring employees with skills is utmost need of the hotel industry, especially for front desk employees (Karatepe \& Ngeche, 2012). Frontline employees have a significant contribution to the hotel industry's success, but unfortunately, most of the frontline staff work under immense stress. Even they face huge difficulty in handling clients (Karatepe et al., 2013). These employees are the presenters of an organization and the ones who meet all the challenges towards serving clients (Kusluvan, 2003). Another issue faced by frontline staff is lower wage rate and high turnover intentions (Nadiri \& Tanova, 2010). Employees who think of switching the job tend to deliver low performance, which can harm customers and employee relations (Bakker \& Demerouti, 2008). Therefore, businesses, especially the hotel sector, are much concerned about employee engagement by imparting their role for organizational success (Shuck \& Wollard, 2010; Bakker \& Demeterouti, 2008). The current research is equipped with literature on engagement in the hotel industry and how the hotel sector can influence employee engagement and identify the predictors through empirical evidence. The current research includes a discussion on work engagement and its predictors in the hotel industry. This research also provides implications for both practitioners and researchers for understanding the engagement of employees in the hotel industry. The Job Demand resource model (JDR) and social exchange theory were used to devise the research model. The main idea of this research was to identify the key predictors of work engagement that came in the name of supportive HRM practices.

\section{Literature Review}

\subsection{Work Engagement}

Though work engagement has not been properly defined, still concept is growing (Saks, \& Gruman, 2014). Kahn (1990) first defined engagement concept as psychological conditions and experience, which helps employees use emotionally and cognitively during role performing. Work engagement or employee engagement are interchangeably used in research. Empirical evidence such as Bakker and Demerouti (2008); Koyuncu et al. (2006) suggest that employees with work engagement are better to perform and remain part of the organization. The role of frontline employees is best suited for work engagement, in which they involve themselves in their work and are enthusiastic. Such a level of engagement is highly needed in hotel employees. Research by Li and Frenkel (2017) and Choo (2007) show that job resources like HRM practices help in promoting work engagement in the hotel sector. Supportive HRM practices such as job security (Senol, 2011; Boya et al., 2008; Krsimer et al., 2005), job crafting (Wrzesniewski \& Dutton 2001), and job satisfaction (Van Den Heuvel et al., 2015). Hence work engagement has been noted as an important concept. Current research also identified the prominence of work engagement in the hotel industry of Oman.

\subsection{Job Security and Work Engagement}

Job security is a factor to which firms provide secure employment to employees. Importance of the job security generate from a situation that influences work behavior. If employees feel insecure, they show negative behavior (Domenighetti et al., 2000; Boya et al., 2008). Empirical evidence has shown a significant effect on work-related outcomes (Senol, 2011; Boya et al., 2008; Sverke et al., 2002; Kraimer et al., 2005). With more job security, employees will show more work engagement (Altinay et al., 2018). Although there is a dearth of literature on this relationship. However, the available literature shows the worth of job security in predicting work engagement. Based on this, the present research proposed:

H1. Job security significantly predicts work engagement 


\subsection{Job Crafting and Work Engagement}

Based on the study by Petrou et al. (2012), job crafting is a behavioral technique used by employees who feel the requirements of changes necessary for jobs to perform. Job crafting can be narrated as a set of activities to make some variations in condition and boundaries to perform the job better (Wrzesniewski \& Dutton 2001) by keeping in view challenges, downfall in demands, and demands or acquiring resources (Tims \& Bakker 2010). Tims and Bakker (2010) stated that person-job fit could be enhanced by adapting different characteristics through job crafting. Wrzesniewski and Dutton (2001) stated that positive results can be generated through job crafting, like increasing gains, performing different acts, and controlling meaningful work. Even goals can be easily achieved through better job crafting (Parker et al., 2010). According to scholarly work by Bakkers, Tims, and Deks (2012); De Beer, Tims and Bakker (2016) that there is a positive connection of job crafting with work engagement. Furthermore, it is debated that when employees redesign work setup to have sufficient resources and be able to perform different tasks, it brings energy, absorption and dedication. Hence based on this, the present research proposed:

H2. Job crafting significantly predicts work engagement

\subsection{Job Satisfaction and Work Engagement}

Reason to select job satisfaction as a predictor of work engagement to find out satisfaction differentiation. According to Macey and Schneider (2008), that job satisfaction is job evaluation and is associated with the state of satisfaction, while, Salanova et al. (2011); Macey and Schneider (2008) stated that work engagement is a state of motivation. So it depends on job evaluation by the employee as to whether he/she is satisfied. Based on SET theory, there is a reciprocal relationship between organization and employee to bring up the attitude that increases satisfaction (Seers et al., 1995). So with higher satisfaction in employees with the job, they tend to increase work engagement. Literature by Kahn (1990) and May et al. (20104) state that employees who see their job as meaningful are more engaged. Besides, Saks (2006) states that suitable job characteristics that favor employees bring more work engagement among employees. According to Alarcon and Lyons (2001); Saks (2006); Tims et al. (2013), job satisfaction which positively associated with the work engagement of the employees. From the literature, it is clear that there is an association between engagement and job satisfaction, but it is still underresearched. Therefore, the current research proposed:

\section{H3. Job satisfaction significantly predict work engagement}

\subsection{Job Security and Job Satisfaction}

Identifying the factors of job satisfaction is a critical area in the investigation. Job security is one of the essential factors studied in the developed world. Additionally, in the case of Covid-19, job loss has been increasing, thus increasing the importance of job security. Moreover, changes in job satisfaction level due to job security are not only created by chances of job loss but it is also from workers' side. When job security is more important than job loss, employees' job satisfaction increases due to increased job security. Job security has been noticed as the most valuable factor as a determinant of job satisfaction. A study based on British households identified job security as an essential aspect of the job (Clark, 2001). Similarly, it is shown that job loss has a negative effect on job satisfaction (Blanchflower \& Oswald, 1999). According to Burke (1991) job security has remained a key determinant of job satisfaction. Based on the given evidence, the present research proposed:

H4. Job security significantly predicts job satisfaction. 


\subsection{Job Crafting and Job Satisfaction}

Job crafting is stated as an employees initiatives to make alterations in job settings to achieve the goals by enhancing resources and lessening the demands at work (Tims et al., 2012). Besides this, job satisfaction refers to a positive response towards the work, which shows that an employee has a positive attitude towards their job. Van Den Heuvel et al. (2015) specified job crafting as a cultivator of job satisfaction. Working conditions are essential elements that influence job satisfaction. A better working environment can enhance job satisfaction (Parvin \& Kabir 2011). From end to end in job crafting, staff of employees can redesign the working environment with their choice and skills, including engagement. De Beer et al. (2016) stated that job crafting is an important factor in increasing job satisfaction. Based on given evidence, the present research proposed:

\section{H5. Job crafting significantly predicts job satisfaction.}

\subsection{Job satisfaction as a Mediator}

Job satisfaction denotes to a pleasurable and positive emotional condition experienced by the employees at work. The association between job crafting and work engagement (Petrou et al., 2018; Tims et al., 2005), The association of job security and work outcomes (Kraimer et al., 2005; Boya et al., 2008; Ahmed et al., 2020; Ahmed 2019a; Ahmed et al., 2018) are studied separately and thus, the potential mediation of job satisfaction appears to be missing. Therefore, the present study attempts to check the indirect effect of job security and job crafting on employee work engagement in mediating job satisfaction in frontline employees in the Oman hotel sector.

Employees with satisfaction with their job perform better in comparison with the remaining employees of the organization for a longer period by showing their engagement with work. Satisfied employees utilize their energy effectively for better performance. Notably, employees' job satisfaction is closely linked with job security and job crafting, leading to work engagement (Alarcon \& Lyons 2001; Saks 2006; Tims et al., 2013). Therefore, job security and job crafting can increase work engagement by the involvement of job satisfaction as an intervention. Keeping in view the significance of job satisfaction, the current research has attempted to inspect the intervening role of job satisfaction in the relationship between job security, job crafting and work engagement. Hence the present study proposed:

H6. Job satisfaction has significant mediating effect in the relationship between job security and work engagement.

H7. Job satisfaction has significant mediating effect in the relationship between job crafting and work engagement.

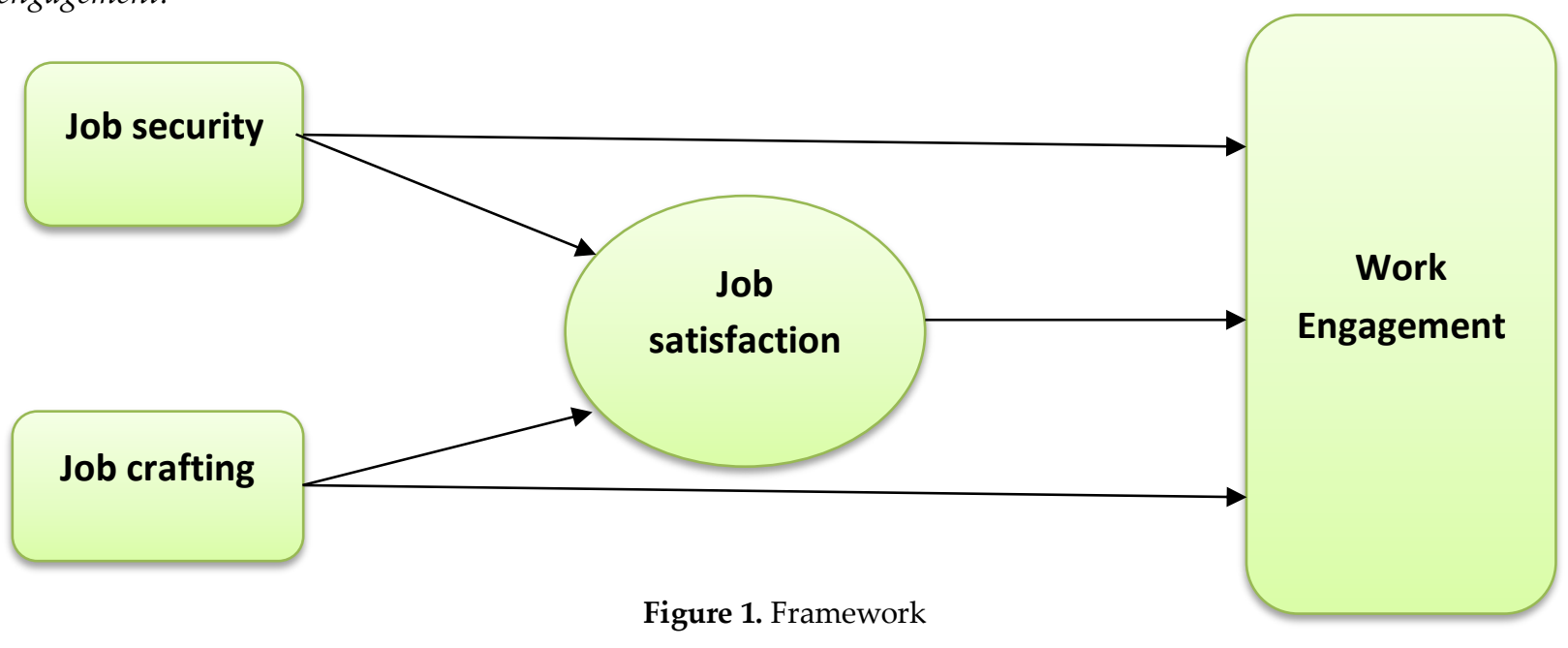




\section{Methodology}

\subsection{Measurement}

Job security was measured through a four-item adapted scale (Delery \& Doty 1996). Reliability for job security was 0.763 . Work engagement was measured through nine items adapted scale (Schaufeli et al., 2006). Reliability for work engagement was 0.948 . Job crafting was evaluated using the 21-item adapted scale (Tims et al., 2012) with a reliability score of 0.88 . Lastly, seven items scale was adapted (Brayfield \& Rothe, 1951) to measure job satisfaction.

\subsection{Population and Sampling}

Hotel industry's employees were the research population, with frontline employees as the primary sample of the study. The exact population was unknown and the expected number of employees in the entire industry could be more than 1000,000. Therefore, Krejcie and Morgan's (1970) sampling table was applied, which gave the sample size of 384. Importantly, for better response rate, an additional $50 \%$ questionnaires were distributed among the target population, making a total of 576 instruments distributed through random sampling approach through the list available in the shape of employees signing in and signing out of the duty. First, hotel managers were contacted to reach the target audience, making the data collection process smooth.

\subsection{Analysis and Interpretation}

The proposed model was assessed through two approaches, measurement and structural model assessment (Anderson \& Gerbing, 1988), as these techniques are being used widely in the research (Ibrahim \& Arshad 2018). At first, assessment of measurement model was executed using the Smart PLS algorithm in which construct reliability and validity were checked. Second, the assessment of the structural model was executed through bootstrapping by using Smart PLS3 to test the proposed hypothesis. We assessed the measurement model (MM) to determine loadings of specific constructs and indicators relevance in PLS analysis, we assessed the measurement model (MM). We also assessed the construct reliability and consistency of the scales.

Table 1. Loadings, CR and AVE

\begin{tabular}{llll}
\hline Variable & Loading & CR & AVE \\
\hline Job Crafting & 0.722 & $\mathbf{0 . 8 9}$ & $\mathbf{0 . 5 6}$ \\
JC-1 & 0.85 & & \\
JC-2 & 0.666 & & \\
JC-3 & 0.636 & & \\
JC-4 & 0.759 & & \\
JC-5 & 0.767 & & \\
JC-6 & 0.641 & & \\
JC-7 & 0.781 & & \\
JC-9 & 0.631 & & \\
JC-10 & 0.865 & & \\
JC-16 & 0.662 & $\mathbf{0 . 6 3 3}$ \\
JC-17 & 0.792 & \\
JC-18 & 0.853 & & \\
JC-19 & 0.854 & & \\
JC-20 & 0.671 & & \\
JC-21 & & & \\
Job Security & 0.818 & & \\
JS1 & 0.839 & & \\
JS2 & 0.819 & & \\
JS3 & &
\end{tabular}




$\begin{array}{llll}\text { JS4 } & 0.699 & \mathbf{0 . 9 2 3} & \mathbf{0 . 7 6 1} \\ \text { Job Satisfaction } & & & \\ \text { JSAT1 } & 0.96 & \\ \text { JSAT2 } & 0.705 & & \\ \text { JSAT3 } & 0.835 & & \\ \text { JSAT4 } & 0.978 & \mathbf{0 . 6 2 6} \\ \text { JSAT5 } & 0.837 & & \\ \text { JSAT6 } & 0.96 & & \\ \text { JSAT7 } & 0.823 & & \\ \text { Work Engagement } & & \\ \text { WE-1 } & 0.829 & \\ \text { WE-2 } & 0.623 & \\ \text { WE-3 } & 0.805 & \\ \text { WE-4 } & 0.849 & \\ \text { WE-5 } & 0.846 & \\ \text { WE-6 } & 0.829 & \\ \text { WE-7 } & 0.523 & \\ \text { WE-8 } & 0.882 & \\ \text { WE-9 } & 0.855 & \end{array}$

Moreover, construct validity was provided by convergent and discriminant validity (DV) of the instruments (Hair, Hult, \& Ringle, 2016). For individual constructs, the estimation of outer loadings and reliability of items was measured by employing the PLS-SEM approach. The range of item loadings resulted between 0.523 to 0.978 , thus fulfilling the recommendations of Hair et al. (2016). However, the most suitable value for outer loading must be equal or greater than 0.70 (Hair et al., 2016; Henseler, Hubona \& Ray, 2016; Ramayah, Cheah, \& Memon, 2018). Convergent validity was also measured (Hair, Matthews, Matthews, \& Sarstedt, 2017). This research has also checked the composite reliability (Hair et al., 2017). The better level of composite reliability is .70 (Hair et al., 2017; Singh \& Prasad, 2018) and above. All the values of CR are mentioned in Table 1 all construct values are lying between the ranges of 0.873 to 0.923 which is above the recommended threshold. AVE is the level of variance between the latent variables and their indicators (Hair et al., 2017; Singh \& Prasad, 2018). The recommended value of AVE is suggested to be no less than 0.50 . Table 1 provides AVE values resulting between 0.56 and 0.761 . Table 1 above provides more detail for this matter.

Accordingly, for measuring the discriminant validity, two approaches were used i.e, Fornell and Larcker (1981) and HTMT were used. Table 3 shows that all diagonal values are higher than values of other rows and columns, representing the DV of the outer model as per the recommendations of Ong and Puteh (2017), except for one value of job crafting to work engagement.

Table 3. Fornell and Larcker (1981) criteria (discriminant validity)

\begin{tabular}{lllll}
\hline Construct & Job Crafting & Job satisfaction & Job Security & W. Engagement \\
\hline Job Crafting & $\mathbf{0 . 7 4 8}$ & & & \\
Job Satisfaction & 0.488 & $\mathbf{0 . 8 7 6}$ & $\mathbf{0 . 7 9 5}$ & \\
Job security & 0.453 & 0.597 & 0.564 & $\mathbf{0 . 7 9 1}$ \\
Work Engagement & 0.91 & 0.661 & \\
\hline
\end{tabular}

Besides Fornell and Larcker (1981) criteria, the current study also used HTMT criteria (Henseler, Ringle \& Sarstedt, 2015) to assess the discriminant validity. Recommended range of HTMT values is less than HTMT0.85 (Clark \& Watson, 1995; Kline 2011) and HTMT0.9 (Gold et al. 2001; Teo et al. 2008). All values in HTMT were found to be less than HTMT0.85. For further detail, HTMT values are presented in table 4.

Table 4. HTMT Criteria

\begin{tabular}{lllll}
\hline & Job Crafting & Job Satisfaction & Job Security & W. Engagement \\
\hline Job Crafting & --- & & & \\
Job Satisfaction & 0.513 & --- &
\end{tabular}


Job security $\quad 0.475$

Work Engagement 0.808

0.475

0.705

0.683

In PLS-SEM, the coefficient of determination is the most appropriate term for the estimation of SM, represented by R-square (Hair et al., 2016; Henseler et al., 2016; Ramayah et al., 2018). The value of the Rsquare (endogenous construct) indicates the model strength. R-square specifies the amount of change by exogenous variable to endogenous variable. According to the available literature, the adequate value of Rsquare must be equal or greater than 0.10 (Ong \& Puteh, 2017). It cannot only evaluate the values of Rsquare for endogenous variables to check the strength of model. Table 5 provide further detail on this.

Table 5. R-Square

\begin{tabular}{lll}
\hline Factor & $\mathbf{R}^{2}$ & Adjusted $\mathbf{R}^{2}$ \\
\hline Job Satisfaction & 0.416 & 0.413 \\
Work Engagement & 0.894 & 0.893 \\
\hline
\end{tabular}

It can be calculated as an increase in the value of square in one variable with respect to other variables (Hair et al., 2017). According to the study of Hair et al. (2017), if the values of $f$ square are $0.35,0.15$ and 0.02 , they specify the effect as large, medium, and small. Table 6 provide further detail on this.

Table 6. F-Square

\begin{tabular}{|c|c|c|c|}
\hline Job Crafting & job Satisfaction & Job Security & Work Engagement \\
\hline Job Crafting & 0.102 & & 3.898 \\
\hline Job Satisfaction & & & 0.343 \\
\hline Job Security & 0.305 & & 0.031 \\
\hline
\end{tabular}

By following the criteria, job crafting has weak effect on job satisfaction and strong effect on work engagement. Similarly, job satisfaction has medium effect on work engagement. Beside this, Job security has medium influence on job satisfaction and weak influence on work engagement.

\subsection{Findings}

Table 7 provides details of the overall results from the structural model

Table 7. Structural Model Assessment

\begin{tabular}{lllll}
\hline Relationship & $\beta$ & t value & p value & Decision \\
\hline H1: JS $\rightarrow$ WE & 0.073 & 2.89 & 0.004 & Significant \\
H2: JC $\rightarrow$ WE & 0.756 & 29.943 & 0.000 & Significant \\
H3: JSAT $\rightarrow$ WE & 0.249 & 6.235 & 0.000 & Significant \\
H4: JS $\rightarrow$ JSAT & 0.474 & 9.804 & 0.000 & Significant \\
H5: JC $\rightarrow$ JSAT & 0.273 & 5.924 & 0.000 & Significant \\
H6: JS $\rightarrow$ JSAT $\rightarrow$ WE & 0.118 & 4.769 & 0.000 & Significant \\
H7: JC $\rightarrow$ JSAT $\rightarrow$ WE & 0.068 & 5.843 & 0.000 & Significant
\end{tabular}

JS= Job security, JC=Job Crafting, JSAT=Job Satisfaction, WE= Work Engagement

Table 7 shows findings of both direct effect (H1 to H5) and indirect effect (H6 and H7). During assessing the direct connection between job security and work engagement, a positive significant relationship was found $(\beta=0.73, t=2.89, \mathrm{p}=0.004)$. Based on the findings, $\mathrm{H} 1$ of the current study was accepted. Moreover, job crafting also resulted in a substantial positive relationship with work engagement $(\beta=0.756, t=29.943, p=0)$; hence $\mathrm{H} 2$ was also accepted. In addition to this, job satisfaction with work engagement in $\mathrm{H} 3(\beta=0.249 \mathrm{t}=6.235, \mathrm{p}=0)$, job security with job satisfaction in $\mathrm{H} 4(\beta=0.474, \mathrm{t}=9.804, \mathrm{p}=$ $0.000)$, and job crafting with job satisfaction in $\mathrm{H} 5(\beta=0.273, \mathrm{t}=5.924, \mathrm{p}=0)$ were also found significant in results. Along with this, current study also tested the mediation of job satisfaction between job security and work engagement relationship in $\mathrm{H} 6(\beta=0.118, \mathrm{t}=4.769, \mathrm{p}=0)$, and job crafting and work engagement relationship in $\mathrm{H} 7(\beta=0.068 \mathrm{t}=5.843, \mathrm{p}=0)$. Hence based on the significant mediation results, it can be narrated that job satisfaction has significantly mediated the link between job security, job crafting, and work engagement. 


\section{Discussion}

The present study was aimed to assess the influence of supportive HRM practices (job security and job crafting) on work engagement both, directly and indirectly through the mediation by job satisfaction in the hotel industry of Oman. The research findings are in line with the empirical evidence between supportive HRM practices and work engagement (Choo, 2007; Li and Frenkel, 2017; Kraimer et al., 2005; Senol, 2011; Wrzesniewski \& Dutton, 2001).

Significant findings in this research show that job security is positively associated with the front-line hotel staff (employees). Results are consistent with existing literature (Wu \& Chen, 2017; van den Heuvel et al., 2015; Kraimer et al., 2005; Senol, 2011; Li and Frenkel, 2017). Results entail that hotel front-line employees are more keenly engaged with work when they have job security. Additionally, the findings propose that when there is fit between person and organization and organization show supportive practices and provide job security even in such pandemic and risky situation under covid-19 employees show more engagement with work. Since people are surrounded by many issues and job insecurity is one of the major issue, that employee in Covid-19 situation do not know that when their boss or organization fires them. In such a situation, if organizations show supportive HRM practices in shape of job security, which reduces major burden of employees, job security employees tend to show more engagement with work.

In the second hypothesis, a significant positive effect of job crafting on work engagement among hotel employees in Oman was found. The empirical evidence from the literature also supports the results of the second hypothesis (Petrou et al., 2018; Tims et al., 2015). Through job crafting, employees can make some changes in daily working style (Wrzesniewski \& Dutton, 2001) if they feel necessary (Petrou et al., 2012). So when the organization supports employees to make some routine changes in work style, make employees motivated and engaged with organization and with their work, it makes them engaged with work. Therefore, more job crafting in the organization should be encouraged to make employees engaged with their work. Similarly, hypothesis 3 also found significant results. Again findings of this research are supported by the literature (Saks, 2006; Alarcon \& Lyons, 2011; Tims et al., 2013). This finding is based on SET. Another way employees with a higher level of satisfaction show dedication and engagement with work. Those organizations who care about their employees and try to achieve goals try to help their staff or employees in their problems will have satisfied employees and have a higher engagement level with work.

Likewise, hypotheses four and five also found a significant positive effect. Again findings of this research are following the pattern in the existing literature. Job security is an important aspect of job satisfaction. The workers with the perception that they have a secure job report a higher level of job satisfaction. Therefore job security has been recognized significant factor in enhancing job satisfaction. This can be concluded that an increased level of job security will increase the level of job satisfaction. Similarly, positive significant association of job crafting with job satisfaction is found in literature and also in this research. In association with a considerable extensive part of job crafting, it has been found that job satisfaction is in association of job crafting. Hence this can be concluded that, job crafting is better predictor of job satisfaction; reason being that in job crafting employees are motivated because they have some sort of option to alter job demands keeping in view the resources of the organizations to perform the particular job.

Since we show that job security and job crafting increase job satisfaction and work engagement, job satisfaction has been linked to increased employee engagement. Hence, job satisfaction on job security and job crafting with work engagement has been mediated significantly. This significance of job satisfaction mediation shows that job satisfaction has a great mediation potential. 


\subsection{Implications}

Results of the research add to literature related to supportive HRM in different ways. This is one of the very rare researches conducted in the hotel industry. Additionally, research has contributed to HRM practices in the Omanese context. Another important implication is that the current study investigated supportive HRM practices (job crafting and job security) in light of social exchange theory and the job demand resource model. Regarding job crafting, employees need two things to know the demands of the jobs and the availability of the resources. Further, these activities lead to engagement.

Practically, this research results will provide a comprehensive model for HR managers in the hotel industry to bring more engaged employees. This research suggests that more job security from the organization and better job crafting by employees will bring more satisfaction towards job for better level of work engagement. Hence hotel management needs to devise strategies to uplift the concept of job crafting and job security for better and enhanced job satisfaction and work engagement. It is highly suggested that employees should be allowed for suitable job crafting, which makes them feel that their organization values them and understands them the real part of the organization so that these employees will show more of work engagement and remain the part of the organization. Furthermore, this research shows that providing a secure job in pandemic situations can sustain more engaged employees. Managers need to develop factors that help employees deliver better services and develop a sense of satisfaction engagement among employees.

\subsection{Limitations and Future Prospects}

Besides several contributions, the present research has some limitations. First, this study was structured on single-time analyses. Future research can be done on multiple time analyses with more or multiple respondents in multiple industries. This study only included simple mediation, future research can be done through adding more serial or sequential mediation or moderation like moderated mediation of mediated moderation. This research only focuses on front-line employees and collected responses from the frontline employees. Future research may therefore include opinion from managers also to find better results.

\section{References}

Ahmed, U. (2017). Job Resources, Job Demands and Developmental Hr in Relation with Work Engagement: The Moderating Role of Service Climate (Doctoral dissertation, Universiti Utara Malaysia).

Ahmed, U. (2019a). Job Demands and Work Engagement: Call for More Urgent Empirical Attention. Annals of Contemporary Developments in Management \& HR (ACDMHR), Print ISSN, 2632-7686.

Ahmed, U. (2019b). Understanding Work Engagement: Simplified Literature Review for Early Scholars. Ahmed, U. understanding work engagement: Simplified literature review for early scholars. Humanities and Social Sciences Review, 7(5), 1073-1081.

Ahmed, U., Awang, Z. B., Hoque, A. S. M. M., Siddiqui, B. A., Dahri, A. S., \& Muda, H. (2018). The mediating role of meaningful work between career growth opportunities and work engagement. International Journal of Academic Research in Business and Social Sciences, 8(11), 1265-1282.

Ahmed, U., Kura, K. M., Umrani, W. A., \& Pahi, M. H. (2020). Modelling the link between developmental human resource practices and work engagement: The moderation role of service climate. Global Business Review, 21(1), 3153.

Alarcon, G.M. \& Lyons, J.B. (2011), "The relationship of engagement and job satisfaction in working samples", The Journal of Psychology, 145(5) 463-480

Albrecht, S.L., Bakker, A.B., Gruman, J.A., Macey, W.H., Saks, A.M., (2015). Employee engagement, human resource management practices and competitive advantage.

J. Organ. Eff. People Perform. 2 (1), 7-35 
Anderson, J. C., \& Gerbing, D. W. (1988). Structural equation modeling in practice: A review and recommended two step approach. Psychological Bulletin, 103(3), 411-423

Bakker, A. B., Tims, M., \& Derks, D. (2012). Proactive personality and job performance: The role of job crafting and work engagement. Human Relations, 65(10), 1359-1378.

Bakker, A.B. \& Demerouti, E. (2007), “The job demands-resources model: state of the art”, Journal of Managerial Psychology, 22(3)309-328

Bakker, A.B. and Demerouti, E. (2008), “Towards a model of work engagement”, Career Development International, 13(3) 209-223

Bakker, A.B., Albrecht, S.L., Leiter, M.P., (2011). Key questions regarding work engagement. Eur. J. Work. Organ. Psychol. 20 (1), 4-28.

Blanchflower, D.G., \& Oswald, A.J. (1999). Well-being, insecurity and the decline of American job satisfaction. Working paper. University of Warwick.

Boya, F.Ö., Demiral, Y., Ergör, A., AKVARDAR, Y. \& De Witte, H. (2008), “Effects of perceived job insecurity on perceived anxiety and depression in nurses", Industrial Health, National Institute of Occupational Safety and Health, 46 (6) 613-619.

Brayfield, A. H., \& Rothe, H. F. (1951). An index of job satisfaction. Journal of Applied Psychology, 35(5), 307-311. doi:10.1037/h0055617

Burke, R.J. (1991), "Job insecurity in stockbrokers: effects on satisfaction and health", Journal of Managerial Psychology, 6(5) 10-16

Chandrakumara, A. \& Sparrow, P. (2004), “Work orientation as an element of national culture and its impact on HRM policy-practice design choices: lessons from Sri Lanka", International Journal of Manpower, 25(6)564-589.

Chen, S., \& Peng, J., (2019) Determinants of frontline employee engagement and their influence on service performance. Int. J. Hum. Resour. Manag. 1-24.

Choo, L.S. (2007), “An empirical investigation into the influence of human resource management practices on work engagement: the case of customer-contact employees in Malaysia", International Journal of Culture, Tourism and Hospitality Research, 8(3). 345-360

Christian, J.S., \& Ellis, A.P., (2013). The crucial role of turnover intentions in transforming moral disengagement into deviant behavior at work. J. Bus. Ethics 119(2), 193-208

Clark, A.E. (2001). What really matters in a job? Hedonic measurement using quit data. Labour Economics 8, 223-242

Clark, L. A., \& Watson, D. (1995). Constructing validity: basic issues in objective scale development. Psychological Assessment, 7(3), 309-319.

De Beer, L. T., Tims, M., \& Bakker, A. B. (2016). Job crafting and its impact on work engagement and job satisfaction in mining and manufacturing. South African Journal of Economic and Management Sciences, 19, 400-412, Available: https://doi.org/10.17159/2222-3436/2016/v19n3a7.

Delery, J.E. and Doty, D.H. (1996), "Modes of theorizing in strategic human resource management: tests of universalistic, contingency, and configurational performance predictions", Academy of Management Journal, 39(4) 802-835

Domenighetti, G., d'Avanzo, B. and Bisig, B. (2000), “Health effects of job insecurity among employees in the Swiss general population", International Journal of Health Services, 30(3), 477-490.

El-Kot, G. and Leat, M. (2008), “Employees' perceptions of supervisory facets: an investigation within an Egyptian context", International Journal of Islamic and Middle Eastern Finance and Management, 1(2)149-165

Fornell, C., \& Larcker, D. F. (1981). Structural equation models with unobservable variables and measurement error: Algebra and statistics. Journal of Marketing and Research 18(3), 382-388.

Gold, A. H., Malhotra, A., \& Segars, A. H. (2001). Knowledge management: an organizational capabilities perspective. Journal of Management Information Systems, 18(1), 185-214.

Gubman, E. (2004), "From engagement to passion for work: the search for the missing person", Human Resource Planning, 27(3) 42-46

Hair Jr, J. F., Matthews, L. M., Matthews, R. L., \& Sarstedt, M. (2017). PLS-SEM or CB-SEM: updated guidelines on which method to use. International Journal of Multivariate Data Analysis, 1(2), 107-123.

Hair, Hult, G. T. M., \& Ringle, C. (2016). A primer on partial least squares structural equation modeling (PLS-SEM): Sage publications. 
Henseler, J., Hubona, G., \& Ray, P. A. (2016). Using PLS path modeling in new technology research: updated guidelines. Industrial Management $\mathcal{E}$ Data Systems.

Henseler, J., Ringle, C. M., \& Sarstedt, M. (2015). A new criterion for assessing discriminant validity in variance-based structural equation modeling. Journal of the Academy Of Marketing Science, 43(1), 115-135.

Huertas-Valdivia, I., Gallego-Burín, A.R., \& Llor' ens-Montes, F.J., (2019). Effects of different leadership styles on hospitality workers. Tour. Manag. 71, 402-420

Ibrahim, Y., \& Arshad, I. (2018). Examining the impact of product involvement, subjective norm and perceived behavioral control on investment intentions of individual investors in Pakistan. Investment Management and Financial Innovations, 14(4), 181-193.

Kahn, W.A. (1990), "Psychological conditions of personal engagement and disengagement at work", Academy of Management Journal, 33(4) 692-724.

Karatepe, O.M. \& Ngeche, R.N. (2012), “Does job embeddedness mediate the effect of work engagement on job outcomes? A study of hotel employees in Cameroon", Journal of Hospitality Marketing and Management, 21(4)440461.

Karatepe, O.M., Karadas, G., Azar, A.K. \& Naderiadib, N. (2013), “Does work engagement mediate the effect of polychronicity on performance outcomes? A study in the hospitality industry in Northern Cyprus", Journal of Human Resources in Hospitality and Tourism, 12(1)52-70.

Kahn, W.A. (1990), "Psychological conditions of personal engagement and disengagement at work", Academy of Management Journal, 33, 692-724

Kline, R. B. (2011). Principles and Practice of Structural Equation Modeling. New York: Guilford Press.

Koyuncu, M., Burke, R.J. \& Fiksenbaum, L. (2006), “Work engagement among women managers and professionals in a Turkish bank: potential antecedents and consequences", Equal Opportunities International, 25(4)299-310.

Kraimer, M.L., Wayne, S.J., Liden, R.C. \& Sparrowe, R.T. (2005), “The role of job security in understanding the relationship between employees' perceptions of temporary workers and employees' performance", Journal of Applied Psychology, 90 (2)389-398

Krejcie, R.V. \& Morgan, D.W. (1970). Determining sample size for research activities. Educational E Psychological Measurement, 30, 607-610

Kusluvan, S. (2003), Managing Employee Attitudes and Behaviors in the Tourism and Hospitality Industry, Nova Science Publisher, New York.

Li, X. and Frenkel, S. (2017), "Where hukou status matters: analyzing the linkage between supervisor perceptions of HR practices and employee work engagement", The International Journal of Human Resource Management, 28(17), 2375-2402.

Macey, W.H. \& Schneider, B. (2008), "The meaning of employee engagement”, Industrial and Organizational Psychology, 1(1)3-30

May, D.R., Gilson, R.L. \& Harter, L.M. (2004), “The psychological conditions of meaningfulness, safety and availability and the engagement of the human spirit at work", Journal of Occupational and Organizational Psychology, 77(1)1137.

Nadiri, H. \& Tanova, C. (2010), "An investigation of the role of justice in turnover intentions, job satisfaction, and organizational citizenship behavior in hospitality industry", International Journal of Hospitality Management, 29(1)33-41.

Ong, M. H. A., \& Puteh, F. (2017). Quantitative Data Analysis: Choosing Between SPSS, PLS, and AMOS in Social Science Research. International Interdisciplinary Journal of Scientific Research, 3(1), 14-25.

Othman, A.E.A. (2009), "Strategic HRM practices: perspectives of Malaysian and Japanese ownedcompanies in Malaysia", Global Business E Management Research,1(1)1-22

Parker, S. K., Bindl, U. K., \& Strauss, K. (2010). Making things happen: A model of proactive motivation. Journal of Management, 36(4), 827-856.

Parvin, M. M., \& Kabir, M. M. N. (2011). Factors affecting employee job satisfaction of pharmaceutical sector. Australian Journal of Business and Management Research, 1, 113-123, Available: https://www.oalib.com/paper/2711954.

Petrou, P., Demerouti, E., \& Schaufeli, W. B. (2018). Crafting the change: The role of employee job crafting behaviors for successful organizational change. Journal of Management, 44(5), 1766-1792.

Petrou, P., Demerouti, E., Peeters, M.C., Schaufeli, W.B. \& Hetland, J. (2012), “Crafting a job on a daily basis: contextual correlates and the link to work engagement", Journal of Organizational Behavior, 33(8)1120-1141 
Ramayah, T., Cheah, J., \& Memon, M. (2018). Partial least squares structural equation modeling (PLS SEM) using SmartPLS 3.0. In An Updated Guide and Practical Guide to Statistical Analysis: Pearson.

Saks, A.M. (2006), “Antecedents and consequences of employee engagement”, Journal of Managerial Psychology, 21(7) 600-619.

Saks, A.M. and Gruman, J.A. (2014), “What do we really know about employee engagement?” Human Resource Development Quarterly, 25(2)155-182

Salanova, M., Llorens, S. \& Schaufeli, W.B. (2011), “'Yes, I can, I feel good, and I just do it!' On gain cycles and spirals of efficacy beliefs, affect, and engagement", Applied Psychology, 60(2) 255-285.

Schaufeli, W.B., Bakker, A.B., Salanova, M., (2006). The measurement of work engagement with a short questionnaire. Educ. Psychol. Meas. 66(4), 701-716.

Schaufeli, W.B., Salanova, M., González-Romá, V. and Bakker, A.B. (2002), "The measurement of engagement and burnout: a two sample confirmatory factor analytic approach", Journal of Happiness Studies, 3(1) 71-92.

Seers, A., Petty, M.M. \& Cashman, J.F. (1995), "Team-member exchange under team and traditional management", Group E Organization Management, 20(1) 18-38.

Senol, F. (2011), "The effect of job security on the perception of external motivational tools: A study in hotel businesses", Journal of Economic and Social Studies, 1(2) 33-60

Shuck, B. \& Wollard, K. (2010), "Employee engagement and HRD: a seminal review of the foundations", Human Resource Development Review, 9(1)89-110.

Singh, \& Prasad, T. (2018). Application of PLS-SEM in Modeling the Significance of Social Valuation in the Determination of Entrepreneurial Intention of Business Management Students. The IUP Journal of Entrepreneurship Development, 8(3).

Sverke, M., Hellgren, J. \& Näswall, K. (2002), “No security: a meta-analysis and review of job insecurity and its consequences", Journal of Occupational Health Psychology, 7(3), 242-264

Teo, T. S. H., Srivastava, S. C., \& Jiang, L. (2008). Trust and electronic government success: an empirical study. Journal of Management Information Systems, 25(3), 99-132.

Tims, M., \& Bakker, A. B. (2010). Job crafting: Towards a new model of individual job redesign. SA Journal of Industrial Psychology, 36(2), 1-9.

Tims, M., Bakker, A.B. \& Derks, D. (2012), “Development and validation of the job crafting scale”, Journal of Vocational Behavior, 80(1) 173-186.

Tims, M., Bakker, A.B. \& Derks, D. (2013), "The impact of job crafting on job demands, job resources, and well-being", Journal of Occupational Health Psychology, 18 (2) 230-240.

Tims, M., Bakker, A.B. \& Derks, D. (2015), "Job crafting and job performance: a longitudinal study", European Journal of Work and Organizational Psychology, 24(6)914-928.

Van den Heuvel, M., Demerouti, E., \& Peeters, M. C. W. (2015). The job crafting intervention: Effects on job resources, self-efficacy, and affective well-being. Journal of Occupational and Organizational Psychology, 88, 1-22, Available: https://doi.org/10.1111/joop.12128.

Wrzesniewski, A. \& Dutton, J.E. (2001), “Crafting a job: Revisioning employees as active crafters of their work", Academy of Management Review, 26(2)179-201.

$\mathrm{Wu}$, B. \& Chen, X. (2017), “Continuance intention to use MOOCs: integrating the technology acceptance model (TAM) and task technology fit (TTF) model", Computers in Human Behavior, 67(1) 221 -232

Xanthopoulou, D., Bakker, A.B., Demerouti, E., \& Schaufeli, W.B., (2009). Work engagement and financial returns: a diary study on the role of job and personal resources. J. Occup. Organ. Psychol. 82 (1), 183200.

C) 2021 by the author(s). Published by Annals of Contemporary Developments in Management \& HR (ACDMHR), under the terms and conditions of the Creative Commons Attribution (CC BY) license which can be accessed at http://creativecommons.org/licenses/by/4.0/. 